\title{
Effect of Dietary Supplementation with Betaine on Growth Performance and Blood Biochemical Profile of Nili-Ravi Buffalo Calves
}

\author{
Zakir Hussain $^{1 \dagger}$, Zahid Iqbal ${ }^{2 * \dagger}$, Nabila Roohi ${ }^{1 \dagger}$ and Sirzamin Khan ${ }^{3 \dagger}$ \\ ${ }^{1}$ Department of Zoology, University of the Punjab, Lahore 54590, Pakistan \\ ${ }^{2}$ Department of Animal Production, Riphah College of Veterinary Sciences, Riphah International University, Lahore 54000, \\ Pakistan \\ ${ }^{3}$ Department of Poultry Sciences, Agriculture University, Peshawar 25120, Pakistan
}

*For correspondence: zahidzizi@gmail.com

$\dagger$ Contributed equally to this work and are co-first authors

Received 03 August 2021; Accepted 14 October 2021; Published 15 December 2021

\begin{abstract}
This study aimed to determine the effect of betaine supplementation on production performance and blood biochemical parameters in calves. Sixty Nili-Ravi calves were randomly divided into four groups: the control group, which received a total mixed ration (TMR) without betaine and three experimental groups that received TMR blended with $0.2,0.4$ and $0.6 \%$ betaine for 8 weeks. Feed and water intake was recorded daily and production performance parameters were recorded on weekly basis. Blood samples were collected weekly and at the end of the experiment. The results showed that feeding betaine to calves increased dry matter intake, body weight gain and average daily gain $(P<0.001)$. Dietary addition of $0.6 \%$ betaine improved feed conversion ratio $(P<0.01)$. Plasma cortisol, superoxide dismutase, and malondialdehyde levels were positively affected $(P<0.05)$ by betaine supplementation as compared to the control group; however, it caused HSP70 levels to decrease $(P<$ 0.05). The results indicated that supplementing betaine to the diet of Nili-Ravi calves enhanced growth performance and improved their antioxidant status. (C) 2021 Friends Science Publishers
\end{abstract}

Keywords: Nili-Ravi calves; Betaine; Growth; Blood biochemical

\section{Introduction}

The great potential of converting low-valued fibrous feedstuff into useful degradable products marked the buffalo (Bubalus bubalis) as a significant contributor to global meat and milk production (Terramoccia et al. 2000). For sustainable buffalo production, calf rearing has been considered an important segment in the livestock sector. Several serious concerns, linked to the initial stage of calf rearing impacting the growth and post maturity performances, are still needed to be dealt with. Besides management and health concerns, the dietary formulations of calves seek substantial attention for better production. In the last decades, several dietary supplements have been extensively evaluated to improve calf health, production, and growth performance (Kaufhold et al. 2000). Among different feed additives, the Betaine (BET) supplementation showed a positive impact on the growth, reproductive, and production performances of different animals and birds (Wang et al. 2019; Alhotan et al. 2021; Zhong et al. 2021). The remarkable influence of BET supplementation on the reduction of heat stress (Hall et al. 2016) could notably improve the buffalo performance which is generally highly affected in summer due to its black body coat. In addition, betaine improves the digestibility of nutrients by maintaining stomach $\mathrm{pH}$, physiological and nutritional functions (Eklund et al. 2005). The purified betaine is highly absorbable in the intestine and has a synergistic effect on nutrient uptakes, improves digestibility of carotenoid, fat, lysine, protein and methionine (Kettunen et al. 2001) which enhance body weight (BW) in different animals (Nezamidoust et al. 2012; Wang et al. 2019).

In simple stomach animals, the role of BET is well established in improving cell integrity and function. As a methyl donor, it supplies the methyl group which is an integral part of many intermediate substances required for the synthesis of protein and energy metabolic pathways (Wang et al. 2019). In ruminants, supplemental BET plays its role in two ways (Hall et al. 2016). Firstly, it is degraded in the rumen to a variable extent and utilized by the rumen microbes resulting in enhanced fermentation activity and increased production of short-chain volatile fatty acids which are a major source of energy for ruminants (Wang et al. 2020a). Under normal conditions, the acetic acid is the ultimate end product of BET but under stressed and hyperosmotic conditions the end product of BET degradation is propionate

To cite this paper: Hussain Z, Z Iqbal, N Roohi, S Khan (2021). Effect of dietary supplementation with betaine on growth performance and blood biochemical profile of Nili-Ravi buffalo calves. Intl J Agric Biol 26:702-706 
which is a glycogenic precursor and an energy source. Secondly, some BET which escapes rumen degradation has a role similar to that seen in simple stomach animals. Studies have been carried out on the use of BET in different farm animals like transition and lactating cows, rams, goats and bulls under normal and stressed conditions with variable results on DMI, milk yield and composition, weight gain, feed conversion efficiency and carcase characters. Relatively, the dietary effect of BET on the production of post-weaning Buffalo calves has scarcely been deliberated. Therefore, the current study was designed to evaluate the effects of dietary supplementation with BET on the growth performance and blood biochemical profile of Nili-Ravi buffalo calves under hot summer environmental conditions of Pakistan.

\section{Materials and Methods}

\section{Experimental design, animals, housing and treatments}

The experiment was conducted at Government Dairy Farm Jhelum, Punjab, Pakistan from July to September 2018. Sixty healthy female buffalo calves having an average BW $71.69 \pm$ $5 \mathrm{~kg}$ at weaning were blocked by BW and allocated to one of the four treatment groups each having fifteen animals, in a randomized complete block design. The animals were previously vaccinated and dewormed as per Farm's policy. Strict bio-security measures were observed with a close watch on health. The calves were fed a basal total mixed ration (TMR) without BET $(\mathrm{CON})$ or with BET as feed additive at the rate of $0.2,0.4$ and $0.6 \%$ of the ration dry matter for eight weeks excluding one week of adaptation. Feed grade BET product 'Betafin ${ }^{\circledR}$ ' (DuPont Animal Nutrition, USA) was procured from 'UM Enterprises Pakistan' in a single consignment and thoroughly mixed at the time of feed preparation for each treatment at the farm feed milling unit. The ingredient composition and nutrient profile of TMR are given in Table 1. All the calves were individually housed in cages under shed and overhead fans were used for ventilation. A measured quantity of drinking water was made available round the clock in steel buckets. TMR was offered once daily in the morning to ensure a minimum $5 \%$ refusal. Temperature and humidity were recorded thrice a day in the morning, afternoon and evening with the help of a digital Temperature Humidity meter (Onway Technology, China).

\section{Body weights and sampling}

The amount of feed and water offered and refused were recorded daily to calculate feed and water intake. The previous day's orts were collected and weighed in the subsequent morning before offering a fresh feed. The dry matter content of TMR was determined fortnightly. All the calves were weighed individually at the start and on weekly basis until the end of the experiment. The weighments were carried out before feeding using a locally manufactured digital weighing scale (Wazan Tech $^{\circledR}$ ). Bodyweight gain was
Table 1: Ingredient composition of total mixed rations (TMR) used in the post-weaning experiment on Nili -Ravi calves

\begin{tabular}{ll}
\hline Ingredients & Inclusion $\%$ \\
\hline Ground maize & 37.0 \\
Wheat straw & 15.0 \\
Maize Gluten 30\% & 13.0 \\
Rice polish & 11.0 \\
Molasses & 5.0 \\
Soybean meal & 16.50 \\
Mineral premix & 1.0 \\
Salt & 0.5 \\
Lime & 1.0 \\
Nutrient composition & \\
DM\% & 88.5 \\
CP & 16.0 \\
ME $(M$. cal/kg) & 2.70 \\
Fat $(\%)$ & 2.5 \\
NDF $(\%)$ & 26.0 \\
ADF $(\%)$ & 15.4 \\
Ash $(\%)$ & 6.91 \\
Ca $(\%)$ & 1.18 \\
P $(\%)$ & 0.59 \\
\hline
\end{tabular}

calculated by subtracting the initial weight from the final weight at the end of each week. Average daily gain (ADG) by each calf during the experimental period was calculated by dividing the total weight gained by the number of days. Feed conversion ratio (FCR) was calculated by dividing average daily dry matter intake (DMI) by the ADG (AbdAllah and Daghash 2019).

\section{Blood sampling and analyses}

Blood samples from the calves were collected via the jugular vein using anticoagulant coated (sodium-heparinized) and plain vacutainer tubes $(10 \mathrm{~mL})$ on weekly basis. The samples were centrifuged for $15 \mathrm{~min}$ at $3000 \mathrm{rpm}$ and the plasma and serum samples harvested were stored at $-20^{\circ} \mathrm{C}$ until analysis. Plasma concentrations of glucose were determined calorimetrically using commercial kits (Alfawassermann, Milano, Italy) as per the manufacturer's instructions. Serum electrolytes and enzymes were measured photo-metrically with an automatic biochemical analyzer (Daytona ${ }^{\circledR}$, Randox) at Combined Military Hospital Laboratory Jhelum Cantonment using various commercial kits according to procedures described by previous researchers (Ježek et al. 2010; Wang et al. 2010a, 2020b). Creatinine level was estimated using an automatic creatinine analyzer (Beckman Synchron LX20 with Synchron LX Creatinine Reagent Kit). The serum cortisol concentration level was determined using a commercial Bovine ELISA test kit (Stress Xpress ${ }^{\circledR}$ Cortisone CLIA Kit). Malondialdehyde (MDA) and superoxide dismutase (SOD) were assayed using a commercial kit (Wang et al. 2010a, 2020b).

\section{Statistical analysis}

Data collected were analyzed in a randomized complete block design using the software SPSS 20 version (SPSS 
Hussain et al. / Intl J Agric Biol, Vol 26, No 6, 2021

Table 2: Effect of betaine supplementation on growth performance of Nili-Ravi calves (Mean \pm SEM)

\begin{tabular}{lllll}
\hline Parameters & BET 0 (Control) & BET 2 & BET 4 & BET 6 \\
\hline Dry matter intake (kg/day) & $3.60 \pm 0.023^{\mathrm{c}}$ & $4.28 \pm 0.025^{\mathrm{b}}$ & $4.32 \pm 0.035^{\mathrm{b}}$ & $4.49 \pm 0.023^{\mathrm{a}}$ \\
Water intake (Litres/day) & $11.72 \pm 0.136^{\mathrm{c}}$ & $12.40 \pm 0.108^{\mathrm{b}}$ & $12.84 \pm 0.045^{\mathrm{a}}$ & $12.98 \pm 0.087^{\mathrm{a}}$ \\
Weight gain (kg) & $22.80 \pm 0.5787^{\mathrm{c}}$ & $26.43 \pm 0.511^{\mathrm{b}}$ & $27.64 \pm 0.868^{\mathrm{b}}$ & $31.84 \pm 0.201^{\mathrm{a}}$ \\
ADG (kg/day) & $0.40 \pm 0.009^{\mathrm{c}}$ & $0.47 \pm 0.008^{\mathrm{b}}$ & $0.49 \pm 0.015^{\mathrm{b}}$ & $0.56 \pm 0.004^{\mathrm{a}}$ \\
FCR & $9.04 \pm 0.24^{\mathrm{b}}$ & $9.00 \pm 0.13^{\mathrm{b}}$ & $8.85 \pm 0.062^{\mathrm{b}}$ & $7.90 \pm 0.07^{\mathrm{a}}$ \\
\hline
\end{tabular}

Different superscripts $(\mathrm{a}, \mathrm{b}, \mathrm{c})$ within the same row indicate significant association $(P<0.01)$ between two different groups. ADG= Average daily gain, FCR=Feed to gain ratio

Table 3: Effect of betaine supplementation on serum enzymes and blood chemical parameters of Nili-Ravi calves (Mean \pm SEM)

\begin{tabular}{lllll}
\hline Parameters & BET 0 (Control) & BET 2 & BET 4 & BET 6 \\
\hline Glucose $(\mathrm{mg} / \mathrm{dL})$ & $5.791 \pm 0.055^{\mathrm{a}}$ & $5.524 \pm 0.066^{\mathrm{a}}$ & $5.589 \pm 0.046^{\mathrm{b}}$ & $5.564 \pm 0.047^{\mathrm{b}}$ \\
Creatinine $(\mathrm{mg} / \mathrm{dL})$ & $11.221 \pm 0.166^{\mathrm{c}}$ & $12.042 \pm 0.104^{\mathrm{a}}$ & $11.995 \pm 0.120^{\mathrm{b}}$ & $12.237 \pm 0.130^{\mathrm{b}}$ \\
Cortisone $(\mathrm{mg} / \mathrm{dL})$ & $13.017 \pm 0.210$ & $13.106 \pm 0.468$ & $13.422 \pm 0.178$ & $13.803 \pm 0.299$ \\
Sodium $(\mathrm{mg} / \mathrm{dL})$ & $136.085 \pm 0.836^{\mathrm{a}}$ & $128.618 \pm 0.975^{\mathrm{b}}$ & $129.616 \pm 1.176^{\mathrm{b}}$ & $125.643 \pm 0.295^{\mathrm{c}}$ \\
MDA (nM) & $1.35 \pm 0.42^{\mathrm{c}}$ & $1.45 \pm 0.20^{\mathrm{b}}$ & $2.06 \pm 0.74^{\mathrm{a}}$ & $2.08 \pm 0.74^{\mathrm{a}}$ \\
SOD (U/L) & $13.07 \pm 0.23^{\mathrm{b}}$ & $13.91 \pm 0.20^{\mathrm{b}}$ & $14.88 \pm 1.87^{\mathrm{a}}$ & $15.08 \pm 0.87^{\mathrm{a}}$ \\
Calcium $(\mathrm{mg} / \mathrm{dL})$ & $3.394 \pm 0.032$ & $3.433 \pm 0.094$ & $3.622 \pm 0.149$ & $4.104 \pm 0.249$ \\
Potassium (mg/dL) & $11.983 \pm 0.126$ & $11.890 \pm 0.029$ & $11.970 \pm 0.060$ & $11.719 \pm 0.074$ \\
\hline
\end{tabular}

2011). The significant association of parameters between four groups was estimated with the implementation of the One-way analysis of variance (ANOVA) method. Verification of significant differences was also done using Tukey's test with a significance level of $\leq 0.05$.

\section{Results}

In this experiment BET supplementation positively $(P<$ 0.05 ) affected the DMI, water intake, growth performance and FCR in buffalo calves (Table 2). Feed conversion ratio (Average daily DMI to average daily gain) was significantly better for BET 6 as compared to Control, BET 2 and BET4. Mean values of various blood chemical parameters and serum enzymes as influenced by the treatments have been presented in Table 3. Serum creatinine concentration remained significantly higher in BET supplemented groups as compared to control.

\section{Discussion}

The results of this experiment are in agreement with those of Lakhani et al. (2020) who indicated that dietary supplementation with BET increased BW gain, DMI and FCR in crossbred cow heifers. A study carried out under the same tropical summer conditions by Deshpande et al. (2020), described a similar growth-promoting effect of BET in Buffalo heifers in the shape of higher $(P \leq 0.05)$ ADG and DMI as compared with control. The findings are in line with several other studies. A $2 \times 2$ factorial study conducted by Wang et al. (2020a) reported 25.2\% higher $(P \leq 0.01)$ ADG and $16.25 \%$ lower FCR by feeding BET supplemented diet to Angus bulls without the addition of rumen-protected folic acid. DiGiacomo et al. (2014) also found a trend $(P \leq 0.05)$ of higher carcase weight in feedlot steers with dietary addition of BET during summer. Another research by Bock et al. (2004) reported increased ADG and dressing percentage of steers. In contrast, a previous study reported that dietary supplementation with $2 \mathrm{~g} / \mathrm{kg}$ BET did not affect relative growth parameters, especially weight gain and average daily gain of 6-month-old calves, however; certain carcase characters like marbling score showed improvement (Loest $e t$ al. 2002). The reason for this difference in performance could be related to the complete degradation of supplemental BET by the rumen microbes in later study restricting the availability of methyl group for the animal (Loest et al. 2002; Nezamidoust et al. 2012). The inability of BET to affect homocysteine remethylation in the said study might also be attributed to the non-availability of a vitamin co-factor like pyridoxine and/or folic acid (Lambert et al. 2004). Improved animal growth rate in current and other studies with BET supplementation could partially be attributed to the increased nutrient digestibility, enhanced microbial fermentation, more production of volatile fatty acids and maintenance of mammalian cell integrity under stressful conditions (Wang et al. 2010b; Hall et al. 2016). Another idea that has been advanced to explain the mechanism by which betaine supplementation improves body performance is that BET improves intestinal function by enhancing the digestive enzymes, ameliorating intestinal morphology, and enriching intestinal microbes (Wang et al. 2018). Feed conversion ratio in this experiment was also improved by the increasing level of BET in the diet which is also consistent with the findings of Chand et al. (2017) for broilers and Yu et al. (2004) for pigs. The possible reason can be due to the accumulation of BET residues in muscle cells and an increase in water retention capacity in muscles (Matthews et al. 2001). In our study, improvement in growth performance can also be correlated with the phenomenon that BET helps in energy and protein metabolism (Metris et al. 2014), improves fiber and other nutrient digestibility, and thus improves growth (Liu et al. 2021). Higher water intake in BET fed animals is also in agreement with Hall et al. (2016). Higher DMI as noticed in our experiment substantiate the earlier findings of Shankhpal et al. (2018) and Deshpande et al. (2020) who also reported higher DMI which positively correlated with ADG in BET supplemented animals. However, the same is in partial agreement with Hall et al. (2016), who reported a higher DMI 
in BET supplemented lactating Holstein cows under thermoneutral environmental conditions but a lower DMI in BET supplemented groups under heat stress. The reason could be species difference and lactation stress in the later study.

Blood biochemical indices are considered a key indicator of animal health status. In the present study, most of the blood biochemical parameters were non-significantly affected by BET addition in buffalo calves' diet (Table 3). Among serum enzymes, creatinine showed significant influences because of dietary supplementation with BET. Likewise, a previous study also concluded that BET has the potential to play a vital role in the synthesis of metabolic substances like creatinine and cortisone by transmethylation reaction converting methyl group into choline and methionine (Ratriyanto et al. 2009). Plasma glucose levels increased significantly with dietary BET at the rate of $0.2 \%$ as compared to control and other treatment groups. The results of the present study are in line with the findings of Abd-Allah and Daghash (2019) who observed an increase in glucose level in Ossimi rams treated with BET supplemented diet. The increase in glucose level might be attributed to the elevation of thyroid hormones including T3 and T4. During the circulation in the body, T4 is mainly transformed into T3 (Zhang et al. 2014). Circulating $\mathrm{T} 3$ is an indicator of metabolic and nutritional status because of the involvement of this hormone in the production of glucose as a result of protein synthesis and lipid metabolism (McDonald 1980). The administration of T3 hormones has been known to increases glucogenesis, glycogenolysis and absorption of glucose from the intestinal tract. In contrast, a lack of residual effect of the BET feeding was noted in the plasma glucose concentration of sheep by DiGiacomo (2011). Malondialdehyde and SOD activity was higher $(P<0.05)$ in the treatment groups as compared to the control group. These results of the present study are in agreement with the findings of (Zhang et al. 2014). Betaine has an antioxidant capacity, which enabled it to scavenge free radicals and protect cells from loss in rats (Lu et al. 2008). Results of the current study indicate a reduction in the reactive oxygen species and free radicals, along with an improvement in the antioxidant capacity. Besides growth performance and serum enzymes, the BET supplementation showed a negative impact on the sodium and potassium concentration, however; calcium concentration was positively increased in treatment groups. These findings are in agreement with the findings of Khattak et al. (2012) who observed a decrease in sodium and potassium concentration in betaine treated group as compared to the control. Betaine supplementation has an influence on sodium concentration by enlarging villi and increasing the thickness of crypts (Lee et al. 2019).

\section{Conclusion}

This experiment has shown that supplementation of BET to the diet of Nili-Ravi calves enhanced growth performance and improved their antioxidant capacity.

\section{Acknowledgements}

The authors are thankful to Military Farms Jhelum authorities, for permitting and facilitating us to conduct this research at their farm.

\section{Author Contributions}

All authors contributed to the study conception and design as well as manuscript writing. Material preparation, data collection and analysis were performed by Zakir Hussain. All authors read and approved the final manuscript for submission.

\section{Conflict of Interest}

The authors declare that they have no conflict of interest.

\section{Data Availability}

Data used in this study can be made available on a serious request to the authors.

\section{Ethics Approval}

All applicable international, national and institutional guidelines for care and use of animals were followed. The experimental protocol was approved by the Animal Care and Use Committee, University of the Punjab, Lahore.

\section{References}

Abd-Allah M and M Daghash (2019). The influence of dietary betaine supplementation to ossimi rams on: (a) growth performance, digestibility coefficients, some blood parameters and activity of thyroid gland. Egypt J Sheep Goats Sci 14:59-68

Alhotan RA, AR Al-Sulaiman, AS Alharthi, AM Abudabos (2021). Protective influence of betaine on intestinal health by regulating inflammation and improving barrier function in broilers under heat stress. Poult Sci100; Article 101337

Bock B, J Brethour, K Harmoney, S Goodall (2004). Influence of betaine on pasture, finishing and carcass performance in steers. Prof Anim Sci 20:53-57

Chand N, S Naz, H Maris, RU Khan, S Khan, MS Qureshi (2017). Effect of betaine supplementation on the performance and immune response of heat stressed broilers. Pak J Zool 49:1857-1862

Deshpande A, S Sigh, YM Somagond, P Sheoran, S Naskar, V Chahal (2020). Physio-biochemical responses and growth performance of buffalo heifers to betaine supplementation during hot humid season under field conditions. Ind J Anim Sci 90:416-423

DiGiacomo K (2011). The physiological and metabolic responses to heat in ruminants. Ph.D. Thesis. Melbourne School of Land and Environment - Agriculture and Food Systems. The University of Melbourne, Australia. http://hdl.handle.net/11343/37196.

DiGiacomo K, R Warner, B Leury, J Gaughan, F Dunshea (2014). Dietary betaine supplementation has energy-sparing effects in feedlot cattle during summer, particularly in those without access to shade. Anim Prod Sci 54:450-458

Eklund M, E Bauer, J Wamatu, R Mosenthin (2005). Potential nutritional and physiological functions of betaine in livestock. Nutr Res Rev 18:3148 
Hall L, F Dunshea, J Allen, S Rungruang, J Collier, N Long, R Collier (2016). Evaluation of dietary betaine in lactating Holstein cows subjected to heat stress. J Dairy Sci 99:9745-9753

Ježek J, M Nemec, J Starič, M Klinkon (2010). Blood profile in cows from small farms with low productivity. Acta Agrar Kaposvár 14:147-152

Kaufhold J, H Hammon, J Blum (2000). Fructo-oligosaccharide supplementation: Effects on metabolic, endocrine and hematological traits in veal calves. $J$ Vet Med Ser A 47:17-29

Kettunen H, S Peuranen, K Tiihonen (2001). Betaine aids in the osmoregulation of duodenal epithelium of broiler chicks, and affects the movement of water across the small intestinal epithelium in vitro. Compar Biochem Physiol Part A Mol Integr Physiol 129:595-603

Khattak FM, T Acamovic, N Sparks, TN Pasha, MH Joiya, Z Hayat, Z Ali (2012). Comparative efficacy of different supplements used to reduce heat stress in broilers. Pak J Zool 44:31-44

Lakhani P, P Kumar, MN Alhussien, N Lakhani, S Grewal, A Vats (2020). Effect of betaine supplementation on growth performance, nutrient intake and expression of igf-1 in karan fries heifers during thermal stress. Theriogenology 142:433-440

Lambert B, E Titgemeyer, C Löest, D Johnson (2004). Effect of glycine and vitamin supplementation on sulphur amino acid utilization by growing cattle. J Anim Physiol Anim Nutr 88:288-300

Lee H, J Shin, Y Choi, K Um, H Park, B Park (2019). Effect of betaine and ascorbic acid in drinking water on growth performance and blood biomarkers in meat ducks exposed to heat stress. S Afr J Anim Sci 49:417-423

Liu C, C Wang, J Zhang, Q Liu, G Guo, W Huo, C Pei, L Chen, Y Zhang (2021). Guanidinoacetic acid and betaine supplementation have positive effects on growth performance, nutrient digestion and rumen fermentation in Angus bulls. Anim Feed Sci Technol 276:114923

Loest C, E Titgemeyer, J Drouillard, C Coetzer, R Hunter, D Bindel, B Lambert (2002). Supplemental betaine and peroxide-treated feather meal for finishing cattle. J Anim Sci 80:2234-2240

Lu X, J Wang, H Wang, S Qu (2008). Effects of betaine on body weight and biochemical index in obese rats fed high-fat diet. Acta Nutr Sin 30:311-312

Matthews J, L Southern, A Higbie, M Persica, T Bidner (2001). Effects of betaine on growth, carcass characteristics, pork quality and plasma metabolites of finishing pigs. J Anim Sci 79:722-728

McDonald LE (1980). Veterinary Endocrinology and Reproduction, $4^{\text {th }}$ edn, pp:58-91. Febiger L (Ed). Philadelphia, USA

Metris A, S George, F Mulholland, A Carter, J Baranyi (2014). Metabolic shift of Escherichia coli under salt stress in the presence of glycine betaine. Appl Environ Microbiol 80:4745-4756

Nezamidoust M, M Alikhani, G Ghorbani, M Edris (2012). Effects of betaine and sulfate supplementation on milk and wool production of naeini ewes. Small Rumin Res 105:170-175
Ratriyanto A, R Mosenthin, E Bauer, M Eklund (2009). Metabolic, osmoregulatory and nutritional functions of betaine in monogastric animals. Asian-Aust J Anim Sci 22:1461-1476

Shankhpal SS, CR Waghela, PL Sherasia, AK Srivastava, V Sridhar (2018). Betaine supplementation and milk production during heat stress in crossbred cows. Ind J Anim Nutr 35:386-390

SPSS I (2011). IBM SPSS statistics for windows, version 20.0. IBM Corp 440, New York, USA

Terramoccia S, S Bartocci, A Amici, F Martillotti (2000). Protein and protein-free dry matter rumen degradability in buffalo, cattle and sheep fed diets with different forage to concentrate ratios. Livest Prod Sci 65:185-195

Wang B, C Wang, R Guan, K Shi, Z Wei, J Liu, H Liu (2019). Effects of dietary rumen-protected betaine supplementation on performance of postpartum dairy cows and immunity of newborn calves. Animals 9; Article 167

Wang C, C Liu, G Zhang, H Du, Z Wu, Q Liu, G Guo, W Huo, J Zhang, C Pei (2020a). Effects of rumen-protected folic acid and betaine supplementation on growth performance, nutrient digestion, rumen fermentation and blood metabolites in angus bulls. Braz $J$ Nutr 123:1109-1116

Wang C, H Liu, C Wang, J Liu, H Liu (2020b). Effects of dietary rumenprotected betaine on lactation performance and serum metabolites of mid-lactation Holstein dairy cows. J Agric Food Chem 68:13154 13159

Wang C, H Liu, Y Wang, Z Yang, J Liu, Y Wu, T Yan, H Ye (2010a). Effects of dietary supplementation of methionine and lysine on milk production and nitrogen utilization in dairy cows. J Dairy Sci 93:3661-3670

Wang C, Q Liu, W Yang, J Wu, W Zhang, P Zhang, K Dong, Y Huang (2010b). Effects of betaine supplementation on rumen fermentation, lactation performance, feed digestibilities and plasma characteristics in dairy cows. J Agric Sci 148:487-495

Wang H, S Li, S Fang, X Yang, J Feng (2018). Betaine improves intestinal functions by enhancing digestive enzymes, ameliorating intestinal morphology and enriching intestinal microbiota in high-salt stressed rats. Nutrients 10:907

Yu D, Z Xu, W Li (2004). Effects of betaine on growth performance and carcass characteristics in growing pigs. Asian-Aust J Anim Sci 17:1700-1704

Zhang L, S Ying, W An, H Lian, G Zhou, Han (2014). Effects of dietary betaine supplementation subjected to heat stress on milk performances and physiology indices in dairy cow. Genet Mol Res 13:7577-7586

Zhong Y, Z Yan, B Song, C Zheng, Y Duan, X Kong, J Deng, F Li (2021). Dietary supplementation with betaine or glycine improves the carcass trait, meat quality and lipid metabolism of finishing mini-pigs. Anim Nutr 7:376-383 